\title{
Reduction in fitness of flea beetles which are homozygous for an autosomal gene conferring resistance to defences in Barbarea vulgaris
}

\author{
PETER W. DE JONG $\dagger+\&$ JENS KVIST NIELSEN*† \\ $\dagger$ Royal Veterinary and Agricultural University, Chemistry Department, Thorvaldsensvej 40, DK-1871 Frederiksberg \\ C, Copenhagen, Denmark and $\ddagger$ Institute of Evolutionary and Ecological Sciences, Section of Evolutionary Biology, \\ University of Leiden, P.O. Box 9516, 2300 RA Leiden, The Netherlands
}

\begin{abstract}
Major resistance genes are present in Danish flea beetle (Phyllotreta nemorum) populations, enabling the beetles to utilize a defended plant, Barbarea vulgaris ssp. arcuata, as a host plant, whereas this plant is unsuitable for beetles lacking the resistance genes. Two lines of beetles carrying a resistance gene have been established which are near-isogenic with a susceptible line. Larval survival of offspring from crosses between flea beetles carrying resistance genes and susceptible beetles, tested in bioassays on the defended $B$. vulgaris, and sex ratios of the survivors, were consistent with the presence of a dominant, autosomal resistance gene in each of the lines. An attempt to produce pure-breeding lines for the autosomal genes revealed that beetles that are homozygous for the resistance gene suffer a high mortality. This result was repeatable for both lines, and when both resistant males and females were used in the crosses. The high mortality was also independent of the plant (defended B. vulgaris or suitable radish) on which the beetles were reared. The results suggest that the time of death of homozygous resistant beetles is variable. The spread and maintenance of resistance genes in flea beetle populations are discussed.
\end{abstract}

Keywords: heterosis, major genes, Phyllotreta, polymorphism.

\section{Introduction}

Many plants are chemically defended against herbivore attack (Futuyma \& Keese, 1992; Futuyma, 1998; references therein, but see Bernays \& Graham, 1988). Specialized herbivores, including phytophagous insects, on the other hand, have evolved adaptations to overcome plant defences (see, e.g. Futuyma \& Keese, 1992). The genetics of the interactions between host plants and phytophagous insects is generally poorly understood (Nielsen, 1997b) but this knowledge is essential for an understanding of the evolution of host plant use (Thompson, 1994). To explain the host plant range of a phytophagous insect, genetic variation in preference for host plants, and performance on these plants need to be studied (Futuyma \& Peterson, 1985; Via, 1990; Sezer \& Butlin, 1998). Inclusion of a new

*Correspondence. Royal Veterinary and Agricultural University, Chemistry Department, Thorvaldsensvej 40, DK-1871 Frederiksberg C, Copenhagen, Denmark.

E-mails: jeni@kvl.dk/pdejong@rulsfb.leidenuniv.nl defended host plant in the diet of a phytophagous insect may result from a mutation that enables the insect to overcome the plant defences (Berenbaum \& Zangerl, 1998; Sezer \& Butlin, 1998). The genes conferring the ability to use the new host plant will spread if the fitness of their carriers is increased. However, costs may also be involved in carrying these genes.

One example of a phytophagous insect that shows an apparently recent inclusion of a defended host plant in the diet is the flea beetle, Phyllotreta nemorum L. (Coleoptera: Chrysomelidae: Alticinae). This beetle attacks various crucifers, on which larvae are leaf miners and adults feed. In Denmark two populations have been discovered where the beetles and their larvae utilize Barbarea vulgaris $\mathrm{R}$. Br. ssp. arcuata (Opiz.) Simkovics (Brassicaceae), G-type (Nielsen, 1997b; de Jong \& Nielsen, 1999; in the remainder of this paper referred to as 'Barbarea'), which is unsuitable as a host plant for the majority of $P$. nemorum (Nielsen, 1992, 1996; 1997b). Crosses between resistant beetles and susceptible conspecifics with respect to the ability of their larvae to complete development on Barbarea in the 
laboratory have revealed that major genes underlie the resistance (Nielsen, 1997b). By combining survival rates of the larvae from crosses between resistant and susceptible beetles with sex ratio data of the survivors, it was concluded that the resistance (R)-genes are located on both sex-chromosomes as well as on autosomes (Nielsen, 1997b). A survey of flea beetle populations in east Denmark revealed that the R-genes are generally rare except in those populations utilizing the defended Barbarea (de Jong \& Nielsen, 1999).

The existence of a polymorphism in nature for the presence of genes with such a large potential advantage (including Barbarea as a host plant) requires an explanation. It is possible that the origin of the ability of $P$. nemorum to utilize the defended Barbarea is recent. Especially if selection pressures favouring the spread of the gene are variable in strength, e.g. because of variability in defence in Barbarea (Nielsen, 1997a), the present distribution of R-genes may be a transient stage. Another possibility with a pedigree of discussion in the literature (e.g. Rausher, 1984; Nielsen, 1996; Tucić et al., 1997; Keese, 1998; Strauss \& Karban, 1998) is that there is a cost to resistance. The present paper presents evidence for deleterious effects of homozygosity for an autosomal R-gene.

\section{Materials and methods}

\section{Plants}

Seeds of Barbarea vulgaris ssp. arcuata (G-type) were collected in Herlev in 1994 (accession no. 3; Nielsen, 1997a). Radish (Raphanus sativus L. cv. Københavns Torve) was purchased from Dæhnfeldt. Plants were grown in a peat-vermiculite mixture and were maintained at $20 \pm 2^{\circ} \mathrm{C}$ and a L18:D6 light-dark cycle. Light was supplied by $400 \mathrm{~W}$ HPI/T-lamps which supplied 160-200 $\mu$ mol quanta $\mathrm{m}^{-2} \mathrm{~s}^{-1}$ at the level of the leaf surface. Plants were 4-8 weeks old and still in the vegetative stage, i.e. before bud formation, when used in bioassays (see below).

\section{Maintenance of insects}

Two lines containing dominant autosomal R-genes (A) originated from the Ejby (E)-population and a line without R-genes originated from the Taastrup (T)population (Nielsen, 1997a,b). Adult beetles were kept at $24 \pm 2^{\circ} \mathrm{C}$ and a L18:D6 light-dark cycle in plastic vials containing a moist gypsum-charcoal bottom layer (Nielsen, 1978; de Jong \& Nielsen, 1999). They were fed three times/week with radish cotyledons or young leaves. Eggs were laid in crevices in the gypsum-charcoal bottom layer. Neonate larvae were used for the bioassays before they had access to any food supplies.

\section{Determination of insect genotype}

The $a a$ genotype is readily identified by its failure to survive as larvae on the G-type of Barbarea (Nielsen, 1997a, 1999). $A A$ and $A a$ genotypes can be identified by backcrossing them with $a$ a beetles and investigating the performance of their offspring on Barbarea. Expected survival rates of offspring from $A A$ and $A a$ beetles are $100 \%$ and $50 \%$, respectively, under these conditions (Fig. 1), and expected sex ratios are $50 \%$ of each sex if the R-genes are autosomal.

Survival of larvae was determined in bioassays using rosette leaves of Barbarea. Leaves were picked and put individually in $25 \mathrm{~mL}$ plastic vials. A small strip of moist

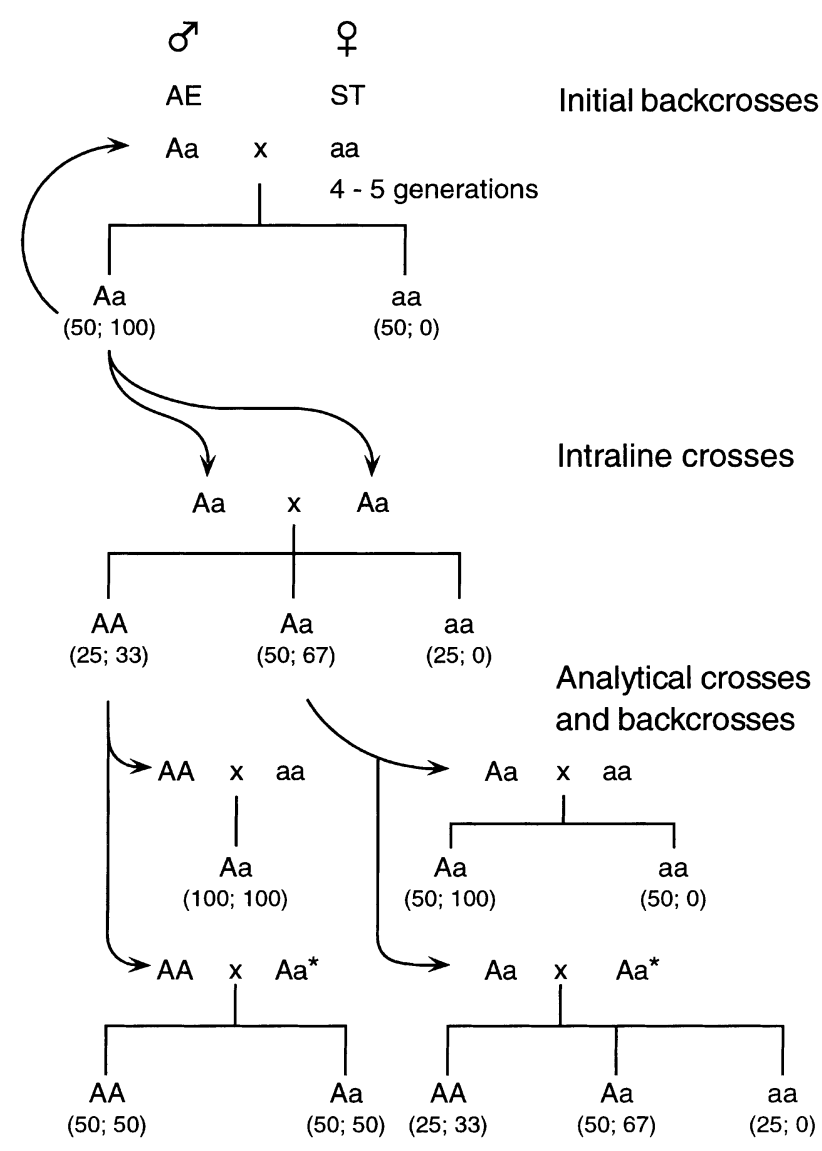

Fig. 1 Diagram of crosses and backcrosses between flea beetles. The first $A a$ males used in the initial backcrosses were the $F_{1}$ from a cross between one field-collected female from Ejby and a male from the ST-line, in each of the two lines. Expected frequencies of offspring when reared on two different plants (radish, Barbarea vulgaris ssp. arcuata) are given under the assumption that $A A$ and $A a$ genotypes survive equally well on B.v. ssp. arcuata. The a genotype is unable to survive on B.v. ssp. arcuata. Aa females (*) used in the analytical crosses originated from the initial backcrosses used for maintenance of the heterozygous lines. 
filter paper was added, and with a moist paint brush five larvae were transferred to each vial. The small vials were stored at $22 \pm 2{ }^{\circ} \mathrm{C}$ and L18:D6. After 3-4 days the leaves were examined using a stereo microscope $(60 \times)$, and the number of surviving larvae was scored. Surviving, resistant larvae had produced a mine, and moved when gently touched with a pair of forceps. Susceptible larvae had not grown at all and were found dead in a tiny mine or on the surface of the leaf. Leaves containing larvae were transferred to $500 \mathrm{~mL}$ vials containing a layer $(5 \mathrm{~cm})$ of moist vermiculite. New Barbarea leaves were added regularly so that larvae could complete their development, and dig into the vermiculite where they pupated. Beetles were sexed upon emergence (see de Jong \& Nielsen, 1999) and sexes were kept separate. The sex ratio was compared to the expectation with an autosomal resistance gene $(50 \%$ females $)$, using the binomial test. Beetles were either used for subsequent crosses immediately, or they were put into diapause as described in de Jong \& Nielsen (1999).

\section{Near-isogenic lines}

A line containing only the $a a$ genotype (ST-line) was developed from the T-population (Nielsen, 1997b). The exact number of founders of the ST-line is unknown because the T-population had already been maintained for several generations in the laboratory before the small proportion of beetles with R-genes was removed by excluding vials with beetles producing some larvae surviving in Barbarea (beginning in 1991). Since then, new males $(\approx 10$ each time) have been collected in Taastrup $c$. every second year and crossed with females from the ST-line. Each individual family was checked for the absence of R-genes (no survival of progeny on Barbarea). Progeny from families without R-genes were later combined with the original ST-line in order to increase the genetic variation and minimize undesirable effects of severe inbreeding. Beetles from the ST-line were kept in groups and $\approx 120$ beetles were maintained at any time to avoid effects of inbreeding.

Two heterozygous lines $(A a)$ were developed from the E-population (AE1 and AE2; Autosomal gene from Ejby). Each line originated from one field-collected female which was crossed with an ST-male $\left(F_{1}\right)$. $F_{1}$ males were used for the first generation of initial backcrosses (Fig. 1), which were continued in order to maintain the heterozygous lines (seven generations for line AE1, four for line AE2). Individual pairs were kept separated and larval survival was tested in bioassays on Barbarea. Ideally, a total number of about 100 larvae per pair was tested in the bioassay. Pairs producing fewer than 30 larvae (e.g. when one parent died) were excluded from the analysis throughout this study. The proportion of pairs excluded from the analysis varied from $\approx 20 \%$ (initial backcrosses and intraline crosses; number of crosses started 86 and 15 , respectively) to $\approx 40 \%$ (analytical backcrosses, see below; 352 were started initially). Failure to produce viable offspring was equally often caused by early death of the ST $(a a)$ as of the experimental beetle ( $A A$ or $A a)$, and it is assumed that pairs producing larvae were an unbiased sample of the pairs which were initially started. When a resistant male was crossed with more than one $a a$ female (because of early death of the female), larval survival data were pooled.

\section{Attempt to develop a homozygous line (AA)}

After at least four or five generations of initial backcrosses for the AE1-line (both generations were used), and four for line AE2, pairs were made of males from each line with females of the same line, with the aim to produce beetles that were homozygous for the autosomal R-genes (Fig. 1: intraline crosses). Pairs were chosen in such a way that inbreeding was avoided, i.e. care was taken to avoid crossing closely related beetles. Larvae from these crosses were either reared through to adults on Barbarea (line AE1; bioassays were performed to measure larval survival) or on intact radish plants (no bioassays; lines AE1 and AE2, Fig. 1). A number of male (lines AE1 and AE2) or female (line AE1) offspring from the intraline crosses were mated with ST-beetles, in order to determine their genotype as described above (Fig. 1: analytical crosses and backcrosses). Controlbioassays were performed where larvae were put on radish, instead of Barbarea, to assess mortality caused by handling. Some offspring from line AE1 were crossed amongst each other, to produce a second generation of intraline AE1 crosses. The procedure described above, with bioassays on Barbarea, and crossing the offspring with susceptible beetles to determine their genotype, was repeated.

\section{Results}

\section{Initial backcrosses}

The results of the initial backcrosses are consistent with the presence in each of the lines AE1 and AE2 of a dominant autosomal R-gene with a major effect on the ability of Phyllotreta nemorum larvae to survive in Barbarea. When males from these lines $(A a)$ were backcrossed with females from the ST-line $(a a)$, the larval survival in bioassays on Barbarea was close to $50 \%$ (Table 1), which is the expected proportion of the $A a$ genotype in the progeny if a single gene is responsible for the effect. Larvae with the $A a$ genotype can survive 
Table 1 Survival rates on Barbarea vulgaris ssp. arcuata of larvae from different generations of flea beetles in the initial backcrosses used for development and maintenance of two near-isogenic lines which are heterozygous for major R-genes. Males from the lines $(A a)$ were mated with $a a$ females in successive backcrosses

\begin{tabular}{lccc}
\hline & $\begin{array}{c}\text { Median \% } \\
\text { larval survival } \\
\text { (range) }\end{array}$ & $\begin{array}{c}\text { Number } \\
\text { of pairs }\end{array}$ & $\begin{array}{c}\text { Number } \\
\text { of larvae } \\
\text { (pairs pooled) }\end{array}$ \\
\hline Line AE1 & & & \\
1 & $42.9(32.9-55.6)$ & 12 & 1140 \\
2 & $43.8(35.4-50.4)$ & 11 & 1287 \\
3 & $41.2(32.6-55.6)$ & 5 & 441 \\
4 & $39.9(35.8-46.7)$ & 5 & 634 \\
5 & $41.0(31.7-45.0)$ & 6 & 774 \\
6 & $44.7(33.3-47.5)$ & 9 & 786 \\
7 & $40.0(32.9-52.8)$ & 8 & 818 \\
Line AE2 & & & \\
1 & $45.8(44.0-47.5)$ & 2 & 221 \\
$2 \dagger$ & $39.8(34.7-40.8)$ & 3 & 545 \\
3 & $39.2(28.0-52.5)$ & 8 & 1149 \\
4 & & & \\
\hline
\end{tabular}

$\uparrow$ No data for second generation.

on Barbarea whereas the aa-genotype cannot. The proportion of survivors and nonsurvivors did not change during 4-7 generations of backcrosses (KruskalWallis one-way analysis of variance by ranks; line AE1: $H=3.26$, d.f. $=6, N=56$ crosses, 7 generations, range $=31.7-55.6 \%, \mathrm{NS}$; line AE2: $H=2.04$, d.f. $=2$, $N=13$ crosses, 3 generations, range $=28.0-52.5 \%$, NS; Table 1), although the original E-genome was diluted by $\approx 50 \%$ at each backcross generation. If the ability to survive on Barbarea had been controlled by additive effects of minor genes at several unlinked loci, it is assumed that survival rates would decrease gradually as a consequence of this dilution of the E-genome (Roush \& Daly, 1990). There was no evidence for skewed sex ratios in the offspring from the backcrosses or from any other crosses throughout this study, when reared on Barbarea and radish (Table 2). Radish is a suitable host plant for all genotypes, and equal sex ratios among imagines reared on this plant are used as evidence for equal sex ratios among neonate larvae. This ratio does not change in beetles reared on Barbarea. Equal sex ratios among beetles reared on Barbarea are expected if the major R-gene is located on an autosome, whereas skewed sex ratios are obtained if the $\mathrm{R}$-genes are located on one of the sex chromosomes (Nielsen, 1997b; de Jong \& Nielsen, 1999).

The results of the initial backcrosses do not rule out the possibility that the observed effects are controlled by a group of closely linked genes rather than a single gene.
Table 2 Sex ratio of offspring reared on Barbarea from pairs involving resistant flea beetles. Offspring were pooled for each type of cross. Binomial tests were performed with an expectation of $50 \%$ females (if an autosomal R-gene is present); none of the sex ratios differed significantly from $50 \%$. For comparison, sex ratios of the offspring from intraline crosses reared on radish are also given; they were not significantly different from $50 \%$

\begin{tabular}{lllcl}
\hline & $\begin{array}{c}\text { Beetles } \\
\text { reared on }\end{array}$ & Line & $\begin{array}{c}\text { Number } \\
\text { of pairs }\end{array}$ & $\begin{array}{c}\text { \% Females } \\
\text { (number of } \\
\text { offspring) }\end{array}$ \\
\hline Initial backcross & Barbarea & AE1 & 58 & $49.1(1160)$ \\
Intraline & Barbarea & AE1 & 15 & $49.7(296)$ \\
Intraline, 2nd & Barbarea & AE1 & 7 & $47.7(65)$ \\
$\begin{array}{l}\text { generation } \\
\text { Initial backcross }\end{array}$ & Barbarea & AE2 & 13 & $50.7(377)$ \\
Intraline & Radish & AE1 & 2 & $51.9(187)$ \\
Intraline & Radish & AE2 & 3 & $46.6(348)$ \\
\hline
\end{tabular}

This distinction is important for our understanding of the origin of the R-genes, but may have few immediate population genetic consequences, because recombination rates seem to be so small that in practice the linked group will be inherited as a single gene. It is also possible that minor genes (modifier genes) influence the phenotypic effects of the major genes and explain some of the observed variation between families within lines. The assumption that a single, dominant $\mathrm{R}$-gene is present in each of the lines (AE1 and AE2) was investigated further by crossing males and females from the same line (intraline crosses, Fig. 1) in an attempt to develop a homozygous line. The results are described for each line separately.

\section{Line $A E 1$}

Survival rates on Barbarea of offspring from the intraline crosses of line AE1 deviated from $75 \%$, which is the expected survival if all larvae with $A A$ and $A a$ genotypes survive (Fig. 1, Table 3). Because $A a$ is known to have high survival rates (see above), this outcome could be explained by lower survival of the $A A$ genotype. To investigate whether this was the case, a number of male offspring from the intraline crosses was reared until adulthood on Barbarea and crossed with ST-beetles ( $a a)$ in analytical backcrosses, to determine their genotype. These crosses confirmed the rarity of the $A A$ genotype. The majority of the families had a larval survival of about $50 \%$ on Barbarea leaves, as expected if the male was of the $A a$ genotype (Fig. 2). Only four families had a substantially larger proportion of survival. Only the males from these four families show evidence of being homozygous for the R-gene, and thus the proportion of 
Table 3 Larval survival in bioassays on Barbarea vulgaris ssp. arcuata (G-type) of crosses between flea beetles from line AE1 (intraline AE1 crosses; 12 pairs)

\begin{tabular}{lrccrl}
\hline Pair & $N$ & \% Survival & Pair & $N$ & $\%$ Survival \\
\hline $\mathrm{a}$ & 136 & $49.3^{* * *}$ & $\mathrm{~g}$ & 165 & $61.8^{* * *}$ \\
$\mathrm{~b}$ & 206 & $62.1^{* * *}$ & $\mathrm{~h}$ & 118 & $45.8^{* * *}$ \\
$\mathrm{c}$ & 69 & $53.6^{* * *}$ & $\mathrm{i}$ & 129 & $58.9 * * *$ \\
$\mathrm{~d}$ & 197 & $43.7^{* * *}$ & $\mathrm{j}$ & 33 & $45.5^{* * *}$ \\
$\mathrm{e}$ & 119 & $49.6^{* * *}$ & $\mathrm{k}$ & 127 & $65.4^{*}$ \\
$\mathrm{f}$ & 144 & $40.3^{* * *}$ & 1 & 48 & 66.7 \\
\hline
\end{tabular}

Asterisks indicate significance of two-tailed binomial tests with an expected proportion survival of $75 \%$ under the assumption that $A A$ and $A a$ survive equally well on this plant; ${ }^{*} P<0.05$;

$* * * P<0.001$; only families with at least 30 larvae were included in the analysis.

males that are homozygous $(6.8 \%)$ is significantly lower than the expected $33 \% \quad\left(\chi^{2}\right.$ goodness-of-fit test, $\left.\chi_{2}^{2}=18.78, N=59, P \ll 0.001\right)$.

The under-representation of homozygous beetles was also apparent when offspring from the intraline crosses were reared on radish (Fig. 3a,c). On this plant, all possible genotypes ( $A A, A a$ and $a a$ ) could survive and the relative ratio was expected to be 1:2:1 (Fig. 1). With analytical backcrosses, a significant departure from this ratio was found in males ( $\chi^{2}$ goodness-of-fit test: $\left.\chi_{2}^{2}=8.82, \quad N=34, P=0.012\right)$ as well as in females $\left(\chi_{2}^{2}=9.08, N=26, P=0.011\right)$. The deviation was caused mainly by a deficiency of the $A A$ genotype. Larval survival in the control-bioassays on radish of the analytical backcrosses (Fig. 3b,d) was high: median $=90.0 \%$

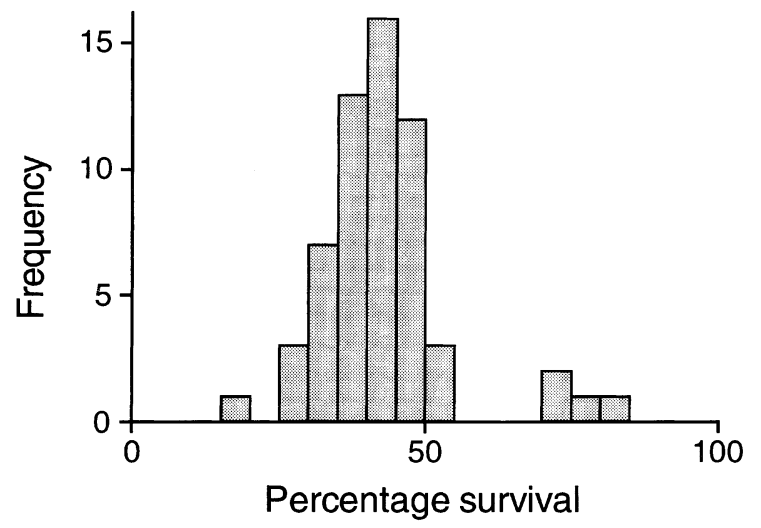

Fig. 2 Frequency distribution of pairs of flea beetles with different larval survival rates on Barbarea vulgaris ssp. arcuata. All pairs consisted of a male offspring from an intraline AE1 cross reared on Barbarea and an ST-female.

for males $(N=18$, range $=73.3-96.0 \%)$ and $86.0 \%$ for females $(N=13$, range $=67.1-100.0 \%)$, showing that background mortality was low.

Some of the male offspring of the intraline AE1 crosses were, after the analytical backcrosses (see above), also crossed with female offspring from intraline AE1 crosses (both sexes reared on Barbarea), to produce a second generation (Fig. 1). The results of the larval survival in bioassays of these crosses are summarized in Table 4 . Males 1, 4 and 5 produced a high survival in the bioassays when crossed with an ST-female, suggesting their genotype to be $A A$. After crossing these males with females from the intraline crosses ( $A A$ or $A a$ ), larval survival is expected to remain high, which was found in three crosses. (a)

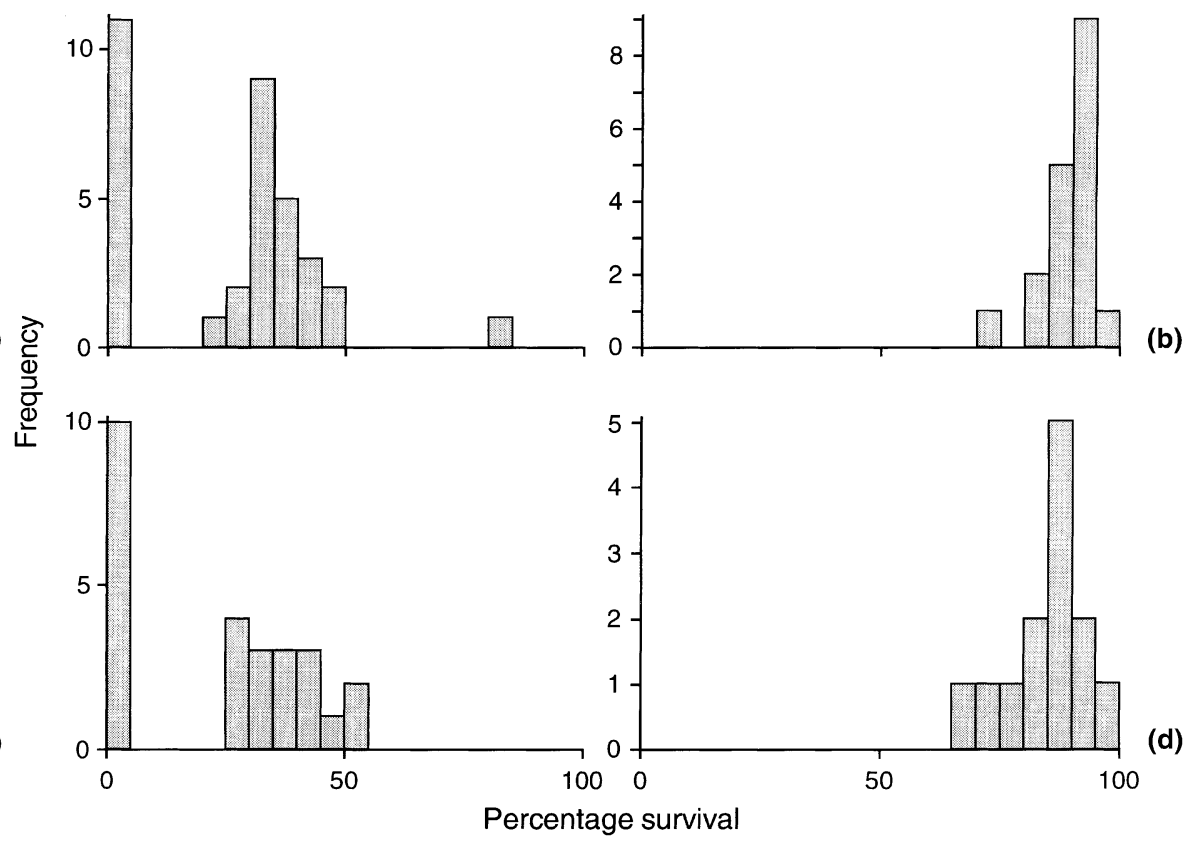

Fig. 3 Frequency distribution of pairs of flea beetles with different larval survival rates on Barbarea and radish, respectively. All pairs consisted of an offspring from an intraline AE1 cross reared on radish, and an ST-beetle. (a) Line AE1 males $\times$ ST-females, bioassays on Barbarea; (b) line AE1 males $\times$ ST-females, bioassays on radish; (c) line AE1 females $\times$ STmales, bioassays on Barbarea; (d) line AE1 females $\times$ ST-males, bioassays on radish. 
Table 4 Larval survival in bioassays on Barbarea vulgaris ssp. arcuata (G-type) of offspring from five individual male flea beetles produced by intraline AE1 pairs crossed with ST- and line AE1-females, respectively. Male 5 has been crossed with one ST-female and three different line-AE1 females $(\mathrm{a}, \mathrm{b}, \mathrm{c})$

\begin{tabular}{|c|c|c|c|c|c|}
\hline \multirow[b]{2}{*}{ Male } & \multicolumn{2}{|c|}{$\times$ ST-female } & \multicolumn{3}{|c|}{$\times$ Line AE1-female } \\
\hline & $N$ & $\%$ Survival & $N$ & $\%$ Survival & $\begin{array}{c}\text { Expected } \% \\
\text { survival } \dagger\end{array}$ \\
\hline 1 & 79 & 82.3 & 72 & 61.1 & $100 \%$ \\
\hline 2 & 140 & 50.7 & 39 & 59.0 & $75-100 \S$ \\
\hline 3 & 108 & 47.2 & 85 & 41.2 & $75-100 \S$ \\
\hline 4 & 177 & 74.0 & 39 & 79.5 & $100 \%$ \\
\hline $5 \mathrm{a}$ & 129 & 77.5 & 78 & 64.1 & $100 \%$ \\
\hline $5 b$ & & & 51 & 84.3 & $100 \ddagger$ \\
\hline $5 c$ & & & 59 & 93.2 & $100 t$ \\
\hline
\end{tabular}

$\dagger$ If $A A$ and $A a$ survive equally well.

$\$$ The male appears to be homozygous (high larval survival when crossed with ST-female) and is expected to produce $100 \%$ resistant offspring when crossed with a line AE1-female.

$\S$ The male seems to be heterozygous $(\approx 50 \%$ larval survival in the cross with ST-female) and is expected to produce $75 \%$ resistant offspring when crossed with a heterozygous line AE1-female, and $100 \%$ if the female is homozygous.

However, in two crosses ( 1 and 5a), the larval survival from the cross with the line AE1-female was significantly lower than with the ST-female $\left(1: \chi_{1}^{2}=8.41, P=0.004 ; 5 \mathrm{a}\right.$ : $\left.\chi_{1}^{2}=4.39, P=0.036\right)$. Crosses 2 and 3 produced a larval survival close to $50 \%$ with an ST-female and did not show any expected increase in survival when males were crossed with a line AE1-female. Some male offspring from this second generation of intraline AE1 crosses (see above) were crossed with ST-females, to test their genotype (analogous to the first generation, see Fig. 1). As in the first generation, the number of homozygous offspring was lower than expected: from 14 offspring from crosses with evidence of a homozygous father (crosses 1 and 5, see Table 4), only two produced a high larval survival in the analytical backcrosses; $\chi_{1}^{2}=7.14, P=0.008, N=14$ ).

\section{Line $A E 2$}

Male offspring from the intraline crosses between AE2 males and females were reared on intact radish plants. The variation in larval survival among the families in the analytical backcrosses was slightly larger than for line AE1 (Fig. 4a). However, only six out of 76 males showed unequivocal evidence of being $A A$. Applying binomial tests, three additional crosses proved to have produced a larval survival slightly, but significantly, higher than $50 \%(57.4 \%, N=204, P=0.02 ; 61.8 \%$, $N=89, P=0.02 ;$ and $62.7 \%, N=220, P<0.001$, respectively; one-tailed tests). These males were also assumed to be homozygous. Two crosses produced a larval survival that was extremely low (both $11.9 \%$, $N=159$ and 101, respectively). The surviving larvae in both of these crosses were often very small. In one of these crosses, the male was crossed with two subsequent ST-females, with one resulting in $0 \%$ survival. Therefore, these two males were assumed to belong to the $a a$ genotype. After thus categorizing the crosses, a $\chi^{2}$ goodness-of-fit test showed a weak, but significant departure from the expected ratio of susceptible, heterozygous resistant and homozygous resistant beetles $\left(\chi_{2}^{2}=7.16, \quad N=76, P=0.028\right)$. As in line AE1 the proportion of homozygous resistant beetles $(11.8 \%)$ was lower than the expected $25 \%$. Figure 4(b) shows that, as before, background mortality was low.

\section{Discussion}

The data on survival in the bioassays (Table 1), combined with the sex ratio of the survivors in the two lines of beetles used in this study (Table 2), are consistent with the presence of a major, dominant autosomal gene in each of the lines conferring the ability to its carriers to complete development on Barbarea. Evidence for the presence of such a gene has been found before in the population from Ejby (Nielsen, 1997b), although autosomal R-genes appeared to be rare compared to R-genes located on the $\mathrm{X}$ and $\mathrm{Y}$ chromosome, respectively.

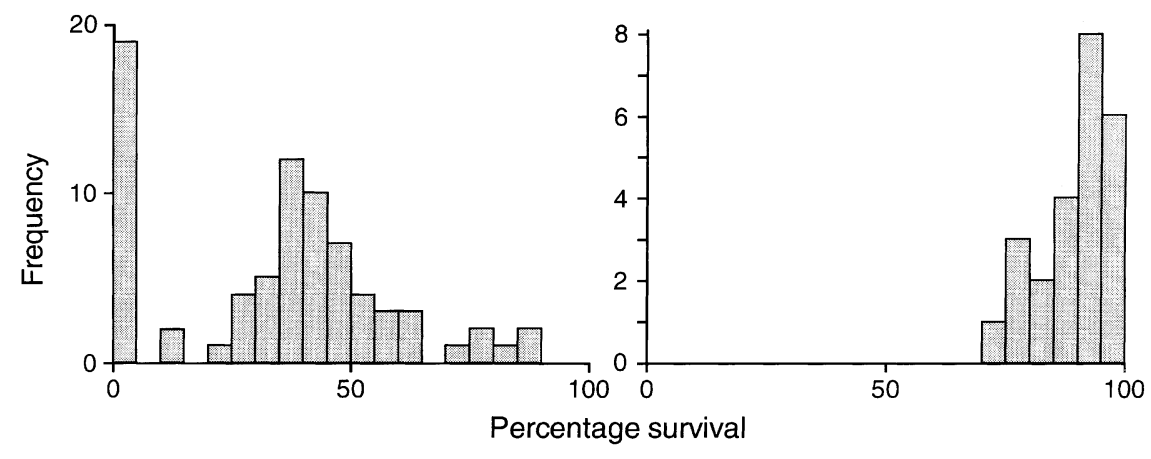

(C) The Genetical Society of Great Britain, Heredity, 84, 20-28.
Fig. 4 Frequency distribution of pairs of flea beetles with different larval survival rates on (a) Barbarea and (b) radish. Pairs consisted of a male offspring from an intraline AE2 cross reared on radish and an ST-female. 
A survey of 12 flea beetle populations from east Denmark demonstrated the presence of major autosomal R-genes in five populations, while it was not possible to distinguish between autosomal- and X-linked genes in four populations (de Jong \& Nielsen, 1999). The genes were generally rare except in two populations (Ejby and Kværkeby) which used the G-type of Barbarea as a natural host plant. Beetles that were apparently homozygous for autosomal R-genes or that contained several R-genes (see below) were found only in these two populations.

The results from the analytical backcrosses revealed that beetles homozygous for autosomal R-genes apparently suffered a high mortality. This result was repeatable, both when beetles were reared on Barbarea and on radish, and for both sexes. The mortality may occur already in the egg stage or later. Death of all $A A$ genotypes in the egg stage should lead to $67 \%$ survival in the bioassays using progeny from intraline crosses $(A a /(A a+a a))$, whereas death during the bioassay would lead to $50 \%$ survival $(A a /(A A+A a+a a))$. Actual survival rates varied within these limits (Table 1) and were lower than $75 \%$ which was expected if $A A$ and $A a$ genotypes had equal chances of survival on Barbarea (Table 1, Fig. 1) or if all $A A$ beetles died after the bioassays. The results suggest that mortality occurs at an early stage, but the analyses of survival rates do not allow a clear distinction between mortality in the egg or early larval stages. The results for line AE1 are clear-cut, but for line AE2 the larval survival in the analytical backcrosses was more variable. A few analytical backcrosses with a larval survival slightly higher than $50 \%$ could either represent homozygous males with an extraordinarily high larval mortality or heterozygous males. These were categorized using a statistical criterion testing for the latter possibility. Overall, then, the results from line AE2 support the conclusion that homozygous resistant beetles are under-represented in the offspring. Our finding of a reduced fitness of beetles which are homozygous for an autosomal R-gene against plant defences may thus constitute a new example of heterosis in a natural insect population.

Other examples are known where mutations of a large effect have a fitness disadvantage when carriers are homozygous for such a gene. In Drosophila, for example, mutations with a large phenotypic effect in heterozygotes cause a low fitness of homozygotes (Orr \& Coyne, 1992). Other examples include 'classical' ones such as sickle-cell anaemia (Cavalli-Sforza \& Bodmer, 1971) and the PGI locus in Colias butterflies (Watt, 1977). These observations have led some authors to the conclusion that mutations of large effect do not play any important role in adaptation ('micromutationism', see Macnair, 1991; Orr \& Coyne, 1992). If any negative pleiotropic effects of the R-gene(s) in P. nemorum are outweighed by the advantage of the ability to use Barbarea as a host plant, the R-gene(s) can spread through the population (see Macnair, 1991).

The under-representation of homozygous beetles in the present experiments could be an effect of the R-genes themselves or of closely linked genes which are deleterious in homozygous condition. After the number of backcrosses in line AE1 and AE2 (4-7), donor DNA may still be associated with the R-genes that were introgressed into the ST-line (Lynch \& Walsh, 1998, p. 409), so that linked genes may be associated with the autosomal R-genes. The proportion of donor DNA that is still associated with the R-genes is difficult to assess without further knowledge about chromosome lengths (P. nemorum has 15 autosomes; Petitpierre et al., 1988; Segarra \& Petitpierre, 1990). The presence of such linked genes seems to be less likely unless they are very widespread in the E-population, i.e. they were found in the founders of two independent lines which were not collected at the same time and therefore are not likely to be closely related. If such genes are abundant in the E-population, there will be a continuous production of homozygous beetles through mating between heterozygous beetles. This will lead to selection against these genes unless they have a beneficial effect in the heterozygous condition, i.e. another example of heterosis. The most parsimonious interpretation therefore seems to be that the reduced fitness of homozygous beetles is an effect of the R-genes themselves. This reduced fitness will have important consequences for the spread and maintenance of the R-genes in natural populations and for the interpretation of the observations that (i) the $\mathrm{R}$-genes are present but rare in flea beetle populations that do not live on Barbarea, and (ii) that beetles which are homozygous or contain different R-genes seem to be abundant in populations living on Barbarea.

The reduced survival of beetles that are homozygous for an autosomal R-gene may, in itself, result in a polymorphic population for the R-gene through heterosis. Heterosis has been thought to represent one of the major mechanisms resulting in a stable polymorphism, but empirical evidence for this mechanism has remained relatively scarce (Hartl \& Clark, 1997; Maynard Smith, 1998) and the importance of this mechanism is controversial (Ridley, 1996). The fitness advantage of carrying an autosomal R-gene will, however, not only be influenced by the ability to use Barbarea as a host plant, and by reduced survival when the gene is present in the homozygous condition. Proximity and abundance of alternative host plant(s) and presence of other R-genes (Nielsen, 1997b, 1999) are expected to influence the fitness of the carrier of a particular R-gene, and hence the maintenance and spread of this gene in the flea 
beetle population. For example, if alternative host plants are absent and no other R-genes are present in the population, the fitness of carriers of an autosomal $\mathrm{R}$-gene which is lethal in the homozygous condition will be high compared to noncarriers. If an alternative host plant is present, however, the relative fitness of the carriers of the R-gene may be reduced.

Beetles which were apparently homozygous or contained several R-genes have been found in two natural flea beetle populations living on the G-type of Barbarea (de Jong \& Nielsen, 1999). The abundance of such genotypes in natural populations may be explained in several ways. First, in our laboratory lines the resistance genes have been extracted from their genetic background, and crossed into a population of beetles that is not adapted to Barbarea. In field populations selection may act on the genetic background (modifier genes) of beetles carrying R-genes to compensate for the adverse effects of being homozygous for the R-genes (see Sezer \& Butlin, 1998). Once an R-gene spreads through a population, beetles that are homozygous for this gene will continuously be produced through matings between heterozygous beetles, even though their fitness may be low. This will then open up the possibility for selection on modifier genes. Secondly, autosomal genes may be present at different loci. In this case our results may be explained by the presence in the population of a resistance gene conferring a reduced fitness when the beetle is homozygous for this gene, as well as other R-genes with no such effect. The gene(s) causing reduced fitness for homozygous carriers may have been isolated in our lines through sampling effects. But, the observation that both of our lines showed a deficiency of homozygous resistant beetles makes this explanation less likely. A third possibility is that two or more autosomal R-genes, each conferring a reduced fitness to homozygous carriers, exist with a complementary effect on resistance. Thus, an individual that is heterozygous at two or more loci may produce offspring with a high survival rate on Barbarea when crossed with a susceptible beetle. If the genes are not tightly linked, repeated backcrossing with susceptible beetles, such as carried out to produce our lines, would result in beetles that are heterozygous for each alternative gene. Such an underlying genetic system accounts for the presence of beetles in the field that produce a high larval survival when crossed with a susceptible beetle, as well as a relative rarity of such beetles after crossing individuals from our lines. Other differences between the laboratory and field conditions may influence the fitness of carriers of R-genes. For example, trade-offs that exist under field conditions may break down in the laboratory, or vice versa. Reduced fitness of beetles which are homozygous for autosomal R-genes may have resulted in the accumulation of several Rgenes in flea beetle populations, including sex-linked genes. A Y-linked gene can never be found in the homozygous condition and no disadvantages have been found for carriers of this gene (Nielsen, 1999). Our data do not exclude the possibility that more than one autosomal locus is involved in the resistance to Barbarea defence. Further observations are needed for a full understanding of the effects of combinations of different R-genes and/or modifier genes on the resistance of $P$. nemorum to Barbarea defence.

\section{Acknowledgements}

We thank Hanne Frandsen for her assistance carrying out the experiments and maintaining the lines, Patrícia do Ó Beldade for her comments on an earlier version of the manuscript, Bas Zwaan for helpful discussion and two anonymous referees for their constructive comments on the manuscript. This work was supported by a grant from the Danish Agricultural and Veterinary Research Council.

\section{References}

Berenbaum, M. R. AND ZANGerL, A. R. 1998. Population-level adaptation to host-plant chemicals: the role of cytochrome P450 monooxygenases. In: Mopper, S. and Strauss, S. Y. (eds) Genetic Structure and Local Adaptation in Natural Insect Populations, pp. 91-112. Chapman \& Hall, New York.

BERNAYS, E. AND GRAHAM, M. 1988. On the evolution of host specificity in phytophagous arthropods. Ecology, 69, 886-892.

CAVAlLI-SFORZA, L. L. AND BODMER, w. F. 1971. The Genetics of Human Populations. W.H. Freeman, San Francisco, CA.

DE JONG, P. W. AND NIELSEN, J. K. 1999. Polymorphism in a flea beetle for the ability to utilize an atypical host plant. Proc. R. Soc. B, 266, 103-111.

Futuyma, D. J. 1998. Evolutionary Biology, 3rd edn. Sinauer, Sunderland, MA.

FUTUYMA, D. J. AND KEESE, M. C. 1992. Evolution and coevolution of plants and phytophagous arthropods. In: Rosenthal, G. A. and Berenbaum, M. R. (eds) Herbivores, their Interactions with Secondary Plant Metabolites, vol. II, Ecological and Evolutionary Processes, 2nd edn., pp. 439475. Academic Press, San Diego, CA.

FUTUYMA, D. J. AND PETERSON, S. C. 1985. Genetic variation in the use of resources by insects. Ann. Rev. Ent., 30, 217-238.

HARTL, D. L. AND ClARK, A. G. 1997. Principles of Population Genetics, 3rd edn. Sinauer, Sunderland, MA.

KEESE, M. C. 1998. Performance of two monophagous leaf feeding beetles (Coleoptera: Chrysomelidae) on each other's host plant: do intrinsic factors determine host plant specialization? J. Evol. Biol., 11, 403-419. 
LYNCH, M. AND WALSH, B. 1998. Genetics and Analysis of Quantitative Traits. Sinauer, Sunderland, MA.

MACNAIR, M. R. 1991. Why the evolution of resistance to anthropogenic toxins normally involves major gene changes: the limits to natural selection. Genetica, 84, 213-219.

MAYNARD SMITH, J. 1998. Evolutionary Genetics, 2nd edn. Oxford University Press, Oxford.

NIELSEN, J. K. 1978. Host plant discrimination within Cruciferae: Feeding responses of four leaf beetles (Coleoptera: Chrysomelidae) to glucosinolates, cucurbitacins and cardenolides. Entomologia exp. appl., 24, 41-54.

NIELSEN, J. K. 1992. Variation in the suitability of Barbarea vulgaris (Cruciferae) for the flea beetle Phyllotreta nemorum. In: Menken, S. B. J., Visser, J. H. and Harrewijn, P. (eds) Proceedings of the 8th International Symposium on InsectPlant Relationships, pp. 205-206. Kluwer, Dordrecht.

NIELSEN, J. K. 1996. Intraspecific variation in adult flea beetle behaviour and larval performance on an atypical host plant. Entomologia exp. appl., 80, 160-162.

NIELSEN, J. K. 1997a. Variation in defences of the plant Barbarea vulgaris and in counteradaptations by the flea beetle Phyllotreta nemorum. Entomologia exp. appl., 82, 25-36.

NIELSEN, J. K. 1997b. Genetics of the ability of Phyllotreta nemorum larvae to survive in an atypical host plant, Barbarea vulgaris ssp. arcuata. Entomologia exp. appl., 82, $37-44$.

NIELSEN, J. K. 1999. Specificity of a Y-linked gene in the flea beetle Phyllotreta nemorum for defences in Barbarea vulgaris. Entomologia exp. appl., 91, 359-368.

ORR, H. A. AND COYNE, J. A. 1992. The genetics of adaptation: a reassessment. Am. Nat., 140, 725-742.

PETITPIERRE, E., SEgARRA, C., YADAV, J. S. AND VIRKKI, N. 1988. Chromosome numbers and meioformulae of Chrysomelidae. In: Jolivet, P., Petitpierre, E. and Hsiao, T. H. (eds) Biology of Chrysomelidae, pp. 161-186. Kluwer, Dordrecht.

RAUSHER, M. D. 1984. Tradeoffs in performance on different hosts: evidence from within- and between-site variation in the beetle Deloyala guttata. Evolution, 38, 582-595.

RIDLEY, M. 1996. Evolution, 2nd edn. Blackwell Science, Cambridge, MA.

ROUSH, R. T. AND DALY, J. C. 1990. The role of population genetics in resistance research and management. In: Roush, R. T. and Tabashnik, B. E. (eds) Pesticide Resistance in Arthropods, pp. 97-152. Chapman \& Hall, New York.

SEGARRA, C. AND PETITPIERRE, E. 1990. Chromosomal survey in three genera of Alticinae (Coleoptera, Chrysomelidae). Cytobios, 64, 169-174.

SEZER, M. AND BUTLIN, R. K. 1998. The genetic basis of host plant adaptation in the brown planthopper (Nilaparvata lugens). Heredity, 80, 499-508.

STRAUSS, S. Y. AND KARBAN, R. 1998. The strength of selection: intraspecific variation in host-plant quality and the fitness of herbivores. In: Mopper, S. and Strauss, S. Y. (eds) Genetic Structure and Local Adaptation in Natural Insect Populations, pp. 156-177. Chapman \& Hall, New York.

THOMPson, J. N. 1994. The Coevolutionary Process. The University of Chicago Press, Chicago.

TUCić, N., MikulJanAC, S. AND STOJKović, O. 1997. Genetic variation and covariation among life history traits in populations of Acanthoscelides obtectus maintained on different hosts. Entomologia exp. appl., 85, 247-256.

VIA, S. 1990. Ecological genetics and host adaptation in herbivorous insects: the experimental study of evolution in natural and agricultural systems. Ann. Rev. Ent., 35, 421-446.

WATT, w. B. 1977. Adaptation at specific loci. I. Natural selection on phosphoglucose isomerase of Colias butterflies: biochemical and population aspects. Genetics, 87, 177-184. 